\title{
Educação popular e educação do/no campo: perspectivas para uma educação inclusiva - a Escola Família Agrícola em Sidrolândia - MS
}

\begin{abstract}
Adenilso dos Santos Assunção ${ }^{1}$, Mara Lúcia Falconi da Hora Bernardelli
${ }^{1}$ Universidade Estadual do Mato Grosso do Sul - UEMS. Unidade Campo Grande. Curso de Licenciatura em Geografia. Avenida Dom Antonio Barbosa (MS-080), 4.155, Conjunto José Abrão. Campo Grande - MS. Brasil. adeassuncao@gmail.com. ${ }^{2}$ Universidade Estadual do Mato Grosso do Sul - UEMS
\end{abstract}

RESUMO. Este artigo é resultado de pesquisa realizada no Curso de Geografia da Universidade Estadual de Mato Grosso do Sul - UEMS. Essa investigação está centrada na experiência Pedagógica da Escola Família Agrícola do município de Sidrolândia, Estado de Mato Grosso do Sul, representando a luta da população campesina no Estado, particularmente os assentados, atores que há décadas lutam por educação como política pública com um fazer pedagógico que não trabalhe com a negação da cultura entendida como rural, que respeite sua forma e estilo de vida, tendo em vista que a educação oferecida a eles quase sempre se apresenta de forma idêntica à oferecida em áreas urbanas. No desenvolvimento, a pesquisa apresenta enfoque qualitativo, tendo como principal aporte a dialogicidade defendida pela prática pedagógica das escolas de alternância. Como procedimento metodológico optou-se pelo levantamento bibliográfico, análise documental, entrevistas e visita in loco. Debateu-se pelas vias da Educação Popular quais possibilidades os movimentos sociais poderiam desenvolver uma educação diferenciada, a partir ou não do aparato do Estado, produzindo conhecimento científico e importante intervenção efetiva na sua realidade e na prática pedagógica que melhor responde aos seus anseios, acontecendo uma educação no e para o campo.

Palavras-chave: Educação do Campo, Educação Popular, Escola Família Agrícola, Alternância. 


\title{
Popular education and rural education: perspectives for inclusive education - the School Família Agrícola in Sidrolândia - MS
}

\begin{abstract}
This article is results of research carried out in the Geography Course of the Universidade Estadual do Mato Grosso do Sul - UEMS. This research is centered in the Pedagogical experience of the Agricultural Family School of the municipality of Sidrolândia, Mato Grosso do Sul State, representing the class struggle of the peasant population in the state, particularly the rural settlers, actors who for decades have been fighting for an education as a public policy with a pedagogical make that does not work with the denial of the culture understood the rural, that respects its life style, considering that the education offered to them almost always presents itself in the same way as offered in urban areas. In the development, the research presents a qualitative approach, having as main contribution the dialogicity defended by the pedagogic practice of the alternating schools. As a methodological procedure, the bibliographical survey, documentary analysis, interviews and an on-site visit were chosen. It was discussed through the views of Popular Education what possibilities social movements could develop a differentiated education, whether or not the State apparatus, producing scientific knowledge and important effective intervention in their reality and pedagogical practice that best respond to their desires, happening an education in and for the countryside.
\end{abstract}

Keywords: Rural Education, Popular Education, School Família Agrícola, Alternation. 


\section{Educación popular y educación del/en el campo: perspectiva para una educación inclusiva - la Escuela Família Agrícola en Sidrolândia - MS}

RESUMEN. Este artículo es resultado de la investigación realizada en el Curso de Geografía de la Universidade Estadual de Mato Grosso do Sul - UESM. Este estudio está centrado en la experiencia pedagógica de la Escuela Familia Agrícola del municipio e Sidrolândia, estado de Mato Grosso do Sul, representando la lucha de la población campesina en el estado, particularmente los asentados, actores que hace décadas luchan por la educación como política pública y como una actividad pedagógica que no trabaje con la negación de la cultura entendidas como rural, que respeta su forma y estilo de vida, llevando en consideración que la educación ofrecida a ellos, casi siempre se presenta de forma idéntica a la ofrecida en las áreas urbanas. En el desenvolvimiento, la investigación presenta un enfoque cualitativo, y tiene como principal aporte la perspectiva dialógica, defendida por la práctica pedagógica de las escuelas de la alternancia. Como procedimiento metodológico se optó por el levantamiento bibliográfico, análisis documental, entrevistas e visita in loco. Se debate por las vías de la Educación Popular que posibilidades los movimientos sociales podrían desarrollar para una construir una educación diferenciada, a partir o no del aparato del Estado, produciendo conocimiento científico que les posibilite una intervención afectiva en su realidad, además de elaborar una práctica pedagógica que mejor responde a sus deseos, aconteciendo una educación él y no para el campo.

Palabras clave: Educación del Campo, Educación Popular, Escuela Familia Agrícola, Alternancia. 


\section{Introdução}

Nos processos sociais recentes que ocorrem no meio rural brasileiro, destacase, nas últimas décadas, a intensificação da implantação de assentamentos voltados à reforma agrária no Brasil, decorrentes das lutas travadas pelos movimentos sociais. É claro que não na proporção desejada por estes movimentos, nem se apresenta na dimensão adequada para atender todo o contingente de brasileiros que ainda se encontra nessa luta e esperam há anos por um pedaço de terra, na fila simbólica de beira de estradas, pelo seu tempo para fazer parte da reforma agrária. Ainda assim, é inegável a existência de uma política.

Ao mesmo tempo em que o processo que fizera "a fila andar" para os agora assentados produz outro movimento nos territórios da reforma agrária: o de luta por direitos até então deles suprimidos, ou seja, luta por educação, pela saúde, pela moradia, pela segurança alimentar, direito inclusive de serem cidadãos brasileiros factíveis de direitos.

Entre os debates mais profícuos que tem acontecido sobre a reforma agrária brasileira, além da luta pela sua ampliação, está à discussão, organização e prática de uma educação do e para o campo. Educação essa que deve ser liberta das amarras do capital, sem a imposição de um viés autoritário, como tem acontecido na educação produzida pelo Estado, salvo raras exceções.

Nesse sentido, a proposta defendida, e em muitos locais colocada em prática pelos movimentos sociais do campo, possibilita que aconteça uma educação junto à classe trabalhadora, a partir da prática da educação popular, vinculada aos seus interesses e desvinculada ideologicamente dos mecanismos utilizados pelas classes dominantes, como uma das formas de garantir sua hegemonia.

Para aprofundar essa discussão, o presente trabalho foi dividido em quatro partes. Inicialmente, refletimos sobre o processo de evolução da luta por uma educação do/no campo, as garantias legais para sua existência, em que defendemos uma educação autônoma organizada e profundamente vinculada aos movimentos sociais camponeses.

$\mathrm{Na}$ segunda parte, discutimos a experiência das Escolas Família Agrícola, amparados na educação popular, enfatizando sua origem, seu fazer pedagógico e sua forma de fazer educação a partir da alternância. Ainda que estejam apoiados no currículo de base comum da educação brasileira, incorporam atividades que incentivam a convivência dos educandos, o desenvolvimento de tarefas, a reflexão e o desenvolvimento do meio em 
que se encontram, centrado na valorização do campo como instrumento capaz de reproduzir vida com qualidade e dignidade, sempre com o intuito da emancipação política, social, cultural do homem e da mulher campesina.

No terceiro momento, enfatizamos a realidade do campo brasileiro, pesquisamos o processo de formação dos assentamentos em Sidrolândia, Estado de Mato Grosso do Sul, com o objetivo de compreendermos sua composição, a realidade vivida pelos assentados, sua relação com o poder político local e as condições em que acontece a educação, as políticas públicas e os projetos, em um município historicamente administrado por latifundiários.

Concluímos nossa pesquisa apresentando como referência em Educação Popular a experiência da Escola Família Agrícola de Sidrolândia no Mato Grosso do Sul, onde, com a pedagogia da alternância, é desenvolvido trabalho educativo exclusivamente aos filhos de assentados do município, apresentando resultados satisfatórios, reconhecidos e premiados no âmbito do Brasil.

\section{Por uma Educação Popular no Brasil}

Até os anos 30 do século passado, o Brasil era um país agrário com sua economia dependente da agro-exportação, sendo seus governos, em todos os âmbitos (federal, estadual e municipal) dominados pelas oligarquias rurais.

Nesse contexto, podemos afirmar que $o$ campesinato brasileiro, historicamente, é refém do desenvolvimento do capitalismo no campo, marcado desde o início da ocupação colonial portuguesa pela concentração da terra e capital em mãos de poucos e pela exploração do trabalhador no desenvolvimento da monocultura em vastas áreas de terra, que tinha e tem até hoje, o objetivo de abastecer com produtos primários principalmente o mercado externo, mais especificamente, portanto, voltado à produção de commodities $^{i}$ (Oliveira, 2007).

Com o surgimento das indústrias, ainda no século XIX, e o seu crescimento exponencial, a partir da década de 1930, esse modelo econômico foi sendo substituído gradativamente, do ponto de vista da ocupação da mão de obra trabalhadora, pois trabalhar no campo significava a exploração do homem, viver em condições precárias e também não ter os mesmos direitos dos trabalhadores urbanos, implantados a partir do governo de Getúlio Vargas.

Especialmente após a década de 1960, com a criação do Estatuto do Trabalhador Rural (Lei n. 4.214, março de 
1963) e do Estatuto da Terra (Lei 4.504, novembro de 1964), já no período da Ditadura Militar e sob uma política de modernização da agricultura, intensificouse a migração campo-cidade e, paulatinamente, o Brasil foi deixando de ser um país majoritariamente rural.

A substituição do modelo agrário exportador pelo modelo urbano industrial caracterizou-se por inúmeras contradições, provocando o crescimento das cidades e, como consequência da industrialização, possibilitou a organização e o fortalecimento da classe trabalhadora, com a conquista de alguns direitos como a carteira de trabalho, instituída pelo decreto $\mathrm{n}^{\circ}$ 21.175, de 21 de março de 1932; a previdência social, criada com o Decreto $\mathrm{n}^{\circ} 7.526$, de 7 de maio de 1945, que dispôs sobre a criação do Instituto de Serviços Sociais do Brasil; o décimo terceiro salário criado pela Lei $\mathrm{n}^{\circ} 4.090$, de 13 de julho de 1962; entre outros.

Os interesses antagônicos existentes no interior da própria classe dominante, entre a burguesia agrária e a industrial, possibilitou que a classe trabalhadora urbana fizesse alianças com a burguesia industrial, tornando viáveis avanços nas conquistas de direitos desses trabalhadores urbanos.

Esses novos direitos concedidos pela classe dominante encobriam, na verdade, outras intenções, pois eram medidas destinadas a propiciar um "novo modo de acumulação", que Oliveira (2003) assim entende:

.. O decisivo é que as leis trabalhistas fazem parte de um conjunto de medidas destinadas a instaurar um novo modo de acumulação. Para tanto, a população em geral, e especificamente a população que afluía às cidades, necessitava ser transformada em "exército de reserva". Essa conversão de enormes contingentes populacionais em "exército de reserva", adequado à reprodução do capital, era pertinente e necessária do ponto de vista do modo de acumulação que se iniciava ou que se buscava reforçar, por duas razões principais: de um lado, propiciava o horizonte médio para o cálculo econômico empresarial, liberto do pesadelo de um mercado de concorrência perfeita, no qual ele devesse competir pelo uso dos fatores; de outro lado, a legislação trabalhista igualava reduzindo - antes que incrementando - o preço da força de trabalho. (p. 38).

O período entre 1930 a 1960 foi marcado por profundas transformações no país, pois surgem os sindicatos e o Partido Comunista foi criado. Intensificaram-se as greves, surgiram as Ligas Camponesas, disseminaram-se os debates culturais e políticos, o movimento por uma educação nova, o movimento pela alfabetização de adultos, campanhas pela democratização da educação, a conquista pelo direito à educação a todas as reformas de base da educação, o movimento de cultura popular, 
entre outras lutas pela mudança social, cultural, política e estrutural da sociedade brasileira.

Destacaram-se nesse período pensadores como Anízio Teixeira, pioneiro na implantação das escolas públicas; Paulo Freire, educador brasileiro reconhecido internacionalmente pelo seu trabalho com a alfabetização de adultos e pela forma como defendia uma educação politizada; Darci Ribeiro, pela defesa da escola pública e pela fundação da Universidade de Brasília. Todos esses educadores, entre outros, apresentaram notáveis contribuições para o pensamento de políticas públicas para a educação brasileira ${ }^{\text {ii }}$.

Nesse contexto, surge um movimento bastante rico para a educação brasileira: a Educação Popular, intimamente ligada à cultura popular, base do projeto de educação da década de 50, com ênfase na autonomia, na emancipação e na justiça social. Para Gadotti (2014), a Educação Popular era à base do novo projeto de nação.

O principal aspecto da Educação Popular se manifesta no compromisso com a população a quem se destina, ao lado das lutas e de ações que favoreçam o acontecimento de políticas que permitam a emancipação das camadas dominadas. Para Wanderley (1991) seria:
... aquela educação que é produzida pelas classes populares ou para ela em função de seus interesses de classe, vinculada aos movimentos populares de forma direta, mas também a organiza pelo estado, incluindo a que ocorre através do Sistema de Educação Formal a adultos e a população em idade escolar. (p. 36).

Nessa perspectiva, a educação pode ser um instrumento para as classes trabalhadoras reelaborarem e executarem uma concepção de mundo vinculada aos seus interesses. Ou seja, uma educação desvinculada ideologicamente dos mecanismos utilizados pelas classes dominantes como uma das formas de garantir sua hegemonia. Nessa ótica, reconhece-se a existência da Educação Popular, em disputa com a classe dominante, ocorrendo, inclusive, dentro dos espaços da educação formal estatal.

Brandão e Bezerra (1987) acreditam que, se aproveitando das escolas públicas, é possível produzir uma Educação Popular formal, oportunizando a transformação social. Ressaltam, inclusive, que os recursos financeiros deste Estado dominador também são garantidos por impostos recolhidos das classes trabalhadoras.

Concordamos com as ideias desses autores, até porque concebemos que a educação formal universal e gratuita é conquista das classes trabalhadoras e a escola oferece aos alunos não somente a 
ideologia dominante, mas também, os instrumentos úteis à sua sobrevivência e emancipação. Assim, o alcance de mais e melhor educação formal possibilitará à classe trabalhadora a elevação do valor de sua força de trabalho e melhores condições de vida.

Nessa concepção, a pressão popular é imprescindível e decisiva na mudança do caráter e da ideologia dessa escola, fortalecendo a luta para a obtenção de recursos, entre os quais aqueles destinados a projetos voltados às classes populares.

Outra forma de percepção da melhoria do ensino seria por meio das lutas desenvolvidas pela classe, que estariam vinculadas diretamente a possibilidades de mudanças políticas e estruturais de suas vidas. Destaca-se aí a importância do Estado na universalização do ensino público elementar, pela extensão que este alcança sobre a escolarização obrigatória e gratuita. Os movimentos populares, desse modo, são fundamentais no financiamento de organizações populares, de atividades educacionais autônomas, no controle da forma e do conteúdo dessa educação, pressionando o Estado.

Sendo assim, torna-se fundamental que as forças populares intervenham na conversão do trabalho pedagógico do educador em favor do trabalho político das classes oprimidas. $\mathrm{O}$ ato de ensinar $\mathrm{e}$ aprender estariam, portanto, diretamente vinculados aos movimentos populares, à sua cultura e identidade, criando-se, assim, um espaço de práticas políticas populares pela educação. A educação, então, se transformaria em mais um instrumento de formação, informação e resistência contra a dominação do capital sobre o trabalho. A educação passaria a interagir, agir e formar atores dessas classes, capazes de interferir no processo de dominação do capital.

Freire (2011) em seu livro "Pedagogia da Autonomia" pressupõe que a educação não é - e tão pouco será neutra; ela sempre trabalhará a serviço de uma ideologia. Educação e a ideologia caminham juntas na construção de crenças, valores e representações simbólicas no interior dos processos educativos. Afirma que "a qualidade de ser política é inerente a sua natureza. É impossível a neutralidade na educação ... $\mathrm{A}$ educação não vira política por causa deste ou daquele educador. Ela é política”. (p. 43).

A questão do trabalho pedagógico se relaciona diretamente com o currículo e ambos estão presentes desde início do debate da Educação do Campo, pois quando os movimentos sociais lutam por uma educação diferenciada, eles percebem que a educação oferecida a partir do aparato do Estado está submetida às vontades e ao controle das elites. 
Outra questão importante que está diretamente relacionada à Educação Popular é o currículo e se fundamenta aí o início do debate da Educação do Campo pelos movimentos sociais.

O currículo tem um papel fundamental na definição da escola que queremos para $\mathrm{o}$ atendimento às classes trabalhadoras. Moreira e Silva (2005) afirmam que o currículo não se refere somente à dimensão técnica, a partir dos métodos empregados, mas que também é guiado por questões sociológicas, políticas e epistemológicas. Sendo assim, é considerado um artefato social e cultural, levando em conta as determinações sociais da história e a contextualização para a população a que se destina.

A disputa pelo controle do currículo, proposta pelo Movimento dos Trabalhadores Sem Terra (MST), nas escolas que atendem aos assentamentos, acontece justamente por perceberem que a classe dominante se utiliza do currículo nas escolas para transmitir suas ideias e representações sobre o mundo, garantindo, assim, a reprodução e perpetuação da estrutura social existente, como instrumento ideológico.

A questão do poder que permeia o currículo não é só uma questão educacional, visto que está intrinsecamente vinculado à dimensão ideológica e política. Silva (1996) defende que:

O currículo é um dos locais privilegiados onde se entrecruzam saber e poder, representação e domínio, discurso e regulação. É também no currículo que se condensam relações de poder que são cruciais para o processo de formação de subjetividades sociais. Em suma, currículo, poder e identidades sociais estão mutuamente implicados. O currículo corporifica relações sociais. (p. 26).

Portanto, o currículo não deve ser analisado de forma neutra e inocente, já que seu papel constitutivo do conhecimento organizado na forma curricular não pode estar preocupado apenas com a organização do conhecimento escolar. O currículo deve ser sempre questionado por uma perspectiva crítica, pois tem conteúdo político.

Nos dias atuais, a questão do currículo encontra-se sob um forte debate impulsionado pela denominada "Escola sem Partido", forma dissimulada e tentativa das elites de transformar professores e escolas em ambiente sem pensamento crítico e sem a possibilidade de discutir uma educação libertadora, desvinculada das ideias e representações de mundo que interessam às classes dominantes $\mathrm{iii}$.

A luta contemporânea pela Educação do Campo, desenvolvida pelos movimentos populares desde a década de 1980, tem início propriamente pelo debate da escola 
que temos e da escola que queremos. É ponto de partida da luta pelo direito à educação aos povos do campo, algumas vezes situados em acampamentos e assentamentos nos mais longínquos grotões, a exemplo dos povos ribeirinhos, dos quilombolas e das áreas indígenas.

Embora sejam os movimentos sociais rurais que ergam a bandeira pela educação do campo, a população rural vai além dos assentados da reforma agrária, ela é composta por trabalhadores remanescentes de quilombolas, pequenos proprietários advindos do processo migratório ao longo dos séculos XIX e XX e outros tantos agricultores que habitam várias regiões brasileiras há décadas e até centenas de anos e não têm relação com os movimentos sociais (Bezerra Neto, 2010, p. 152).

Entretanto, a bandeira da Educação do Campo nasce com a retomada da luta pela terra no Brasil, no final do governo militar, entre os anos de 1979 e 1984, com ocupações e acampamentos, além da luta aprofundada com o nascimento institucional do MST em 1984 (Fernandes, 1998). Movimento esse que sempre se preocupou com a educação de seus filhos, desde os acampamentos até os assentamentos. $\mathrm{O}$ fato de empunharem essa bandeira e lutarem por outra forma de educação advém de enxergarem a necessidade das crianças serem escolarizadas e pela compreensão de que a educação é direito de todos, mas que deve ser libertadora, ou seja, possibilitar uma visão de mundo que permita a autonomia.

Caldart (1997) defende que a própria luta pela terra acaba gerando um nível de consciência das necessidades sociais, que rapidamente faz surgir novas demandas, entre elas, a necessidade de professores identificados com a realidade e a luta do movimento.

Para Bezerra e Bezerra Neto (2007), o MST tem lutado por uma melhor equalização na distribuição da renda brasileira por meio da reforma agrária, como também tem visto a educação como condição essencial para o acesso à igualdade política e o direito à cidadania, considerando necessária uma profunda reforma, tanto no aparelho do Estado, quanto nos mecanismos de acesso à sua estrutura e bens ofertados. Dessa maneira, o MST não reivindica qualquer educação, mas uma educação inclinada para o homem do campo, que lhe permita compreender as causas de suas dificuldades e os mecanismos de dominação usados pelas classes dominantes.

A Educação do Campo vem se constituindo ao longo do tempo com conquistas que se iniciaram com a Lei de Diretrizes e Bases da Educação Nacional, aprovada em dezembro de 1996, Lei $n^{\circ}$ 9.394, a LDB ou Lei Darcy Ribeiro, que no Título V, Capítulo II, art. 
28, permite adequações da escola à vida do campo:

Na oferta de educação básica para a população rural, os sistemas de ensino promoverão as adaptações necessárias à sua adequação às peculiaridades da vida e de cada região, especialmente:

I - conteúdos curriculares e metodologias apropriadas á reais necessidades e interesses dos alunos da zona rural;

II - organização escolar própria, incluindo adequação do calendário escolar às fases do ciclo agrícola e às condições climáticas;

III - adequação à natureza do trabalho na zona rural.

Entretanto, essa flexibilização não se concretiza na realidade apenas em mudanças circunstanciais no ensino que acontece no campo, mantendo-se as escolas funcionando com as mesmas características das escolas urbanas, com conteúdos voltados a temas urbanos e, principalmente, com os referenciais curriculares voltados aos interesses das classes sociais hegemônicas, ou seja, para a manutenção do status quo e em desfavor da cultura campesina.

Foram essas características e a perspectiva de superação desse quadro imposto aos estudantes do campo, considerando as condições adversas a que são submetidos os filhos de pequenos produtores rurais para terem acesso à educação, que levaram alguns movimentos sociais a debaterem nacionalmente tal questão. Dessa forma, diversas entidades como o Movimento dos Trabalhadores Rurais Sem Terra - MST, em conjunto com outros organismos, inclusive internacionais, como o Fundo das Nações Unidas para a Infância - UNICEF, a Organização das Nações Unidas - UNESCO, além da Universidade de Brasília - UNB, a Conferência Nacional dos Bispos do Brasil - CNBB, promoveram a $1^{\mathrm{a}}$ Conferência Nacional - Por uma Educação Básica do Campo, que aconteceu no Centro de Treinamento Educacional - CIT, na cidade de Luziânia - GO de 27 a 31 de julho de 1998, conforme Gonzales, Arroyo e Fernandes (1999).

Os debates ocorridos na primeira conferência produziram a aprovação, pelo Conselho Nacional de Educação em 04/12/2001, das Diretrizes Operacionais para a Educação Básica nas Escolas do Campo - Resolução no 01, de 03 de abril de 2002/CNE/MEC, homologadas pelo Ministério da Educação em 12/12/2002. Constituiu-se, dessa forma, como fundamento legal para a prática nas escolas do campo de uma educação diferenciada nas áreas rurais brasileiras.

A Resolução $\mathrm{n}^{\circ} 01$ do Conselho Nacional de Educação está envolta de simbologia importante para os povos do campo, principalmente pelo seu papel legal, que visa oportunizar a essa população condições de fato e direito de lutarem para 
que aconteça nas escolas do campo uma educação condizente com a sua realidade e, o mais importante, define que a educação deve ser do e para o campo.

$\mathrm{O}$ artigo primeiro da Resolução institui as Diretrizes Operacionais para a Educação do Campo. No artigo segundo afirma que a Resolução é um conjunto de princípios e de procedimentos para que aconteça a adequação dos projetos das escolas do campo à realidade do campo. No artigo quinto é definido que as propostas pedagógicas das escolas do campo devem respeitar as diversidades e diferenças existentes, nos seus aspectos sociais, culturais, políticos, econômicos, de gênero, geração e etnia (CNE. Resolução CNE/CEB 1/2002).

Constitui-se, ainda, como um avanço na Resolução a liberdade para que as propostas pedagógicas de cada escola se organizem e se desenvolvam além dos ambientes escolares, orientando para que o calendário escolar aconteça respeitando as necessidades de cada comunidade e as condições climáticas de cada região.

O principal entrave para que a Resolução não seja colocada em prática nas escolas do campo está relacionado à forma como ficou determinado no artigo sexto da deliberação, repassando ao poder público municipal e estadual a responsabilidade em executar a política de Educação do Campo, sem, no entanto, estipular prazo limite para sua completa implementação.

No entanto, pode-se afirmar que a Resolução $\mathrm{n}^{\mathrm{o}} 1$ (2002) do Conselho Nacional de Educação, órgão deliberativo das políticas públicas em educação no Brasil, é na atualidade, o principal instrumento dos movimentos campesinos para buscarem um currículo diferenciado para o campo, como uma gestão democrática, a autonomia escolar e o fortalecimento dos conselhos escolares, bem como os projetos institucionais que abarquem as demandas dos movimentos sociais do campo.

\section{A Construção das EFAS e sua Importância na Luta pela Educação no Campo}

Com o marco legal para Educação do Campo deliberado, ficam evidentes as diferenças entre a educação rural até então existente e a que se propõe. Para Camacho (2011) tratava-se de uma educação domesticadora, neoliberal e urbanizada, comprometida com a reprodução do processo de manutenção da ordem estabelecida, de desterritorialização do campesinato e de subordinação ao capital.

A realidade atual das escolas do campo nos permite afirmar que a educação ainda é vinculada aos interesses hegemônicos, pois a cultura dominante é disseminada no meio rural como forma de 
estabelecer e exaltar a cultura urbana, com o objetivo de superar a cultura camponesa, que é desvalorizada e colocada como sendo "atrasada".

Para Leite (2002), a educação rural sempre procurou suprimir a cultura dessa população, tanto que os jovens que conseguem frequentar a escola acabam saindo da área rural, com o agravante de que a maioria não tem o desejo de retornar.

É com essa percepção que os movimentos começam a pensar e executar alternativas de organização e funcionamento de escolas no campo, com o objetivo de fortalecer o movimento e a luta camponesa, propondo uma educação humana e emancipatória, articulada com a vida, o trabalho, a cultura, os saberes e as práticas sociais existentes de forma secular no campo brasileiro. Uma educação preocupada com a formação integral do aluno, valorizando o campo, seus atores e considerando os saberes historicamente construídos.

Fernandes (2002) defende que devemos pensar o mundo a partir do lugar em que vivemos, pois dessa forma, construímos nossas identidades, fortalecemos e formamos nossa cultura. Preservar a cultura estaria diretamente relacionado à defesa desse território imaterial, estabelecendo bandeiras dentro do território material, onde acontece a produção e reprodução da vida.

Para Caldart (2002), a Educação do Campo é:

... a luta do povo do campo por políticas públicas que garantam o seu direito à educação, e à uma educação que seja no e do campo. No: o povo tem o direito a ser educado no lugar onde vive; Do: o povo tem direito a uma educação pensada desde o seu lugar e com a sua participação, vinculada à sua cultura e às suas necessidades humanas e sociais ... não pode ser tratada como serviço, nem como política compensatória; muito menos como mercadoria. ( $\mathrm{p}$. 8).

O movimento por uma educação diferenciada se acentua principalmente, porque os atores do campo percebem que mesmo com a promulgação da LDB e as deliberações do $\mathrm{CNE}$ - o poder público não se empenhava em implantar as alterações que se adequavam à realidade e às necessidades campesinas.

O surgimento das Escolas Famílias Agrícolas - EFAS - iniciou-se no Brasil em 1968, sendo posteriormente apropriado pelos movimentos sociais do campo. Segundo Almeida Pinto e Germani (2013), é um modelo originário da França (1935), como proposta de pensar uma educação significativa para os jovens do campo, em que ocorre o revezamento entre os tempos de aprendizagem escolar e de trabalho produtivo, sendo denominada de Pedagogia da Alternância. 
Segundo Queiroz (2004, p. 16-17), na década de 1930, os camponeses franceses passavam pelos mesmos problemas que os campesinos brasileiros em tempos atuais, viviam à margem de políticas públicas, com destaque para a educação, cujo Estado Francês também apresentava aos camponeses um modelo urbano de educação. Ainda que a realidade da época fora o estopim para que os movimentos do campo criassem uma proposta “... que atendesse a realidade e cultura idiossincráticas do grupo campesino, que valorizasse o meio rural, que diminuísse a taxa de evasão escolar e de migração para os centros urbanos e que promovesse o desenvolvimento da agricultura familiar e das comunidades".

A experiência francesa naquele período já era alicerçada na pedagogia da alternância, que Ribeiro (2010, p. 292) explica: "pedagogia da alternância, em tese, articula prática e teoria em uma práxis. Esse método, em que se alternam situações de aprendizagem escolar com situações de trabalho produtivo".

Para Pessotti (1978, p. 128), a experiência das Escolas Família Agrícola chega ao Brasil,

... por meio de ação do Movimento de Educação Promocional do Espírito Santo (MEPES), o qual fundou as então Escolas Famílias Rural de Alfredo Chaves, Escola Família Rural de Olivânia, esta última no município de Anchieta. O objetivo primordial era atuar sobre os interesses do homem do campo, principalmente no que diz respeito à elevação do seu nível cultural, social e econômico.

O Website da Associação Mineira das Escolas Família Agrícola de Minas Gerais (AMEFA) ${ }^{\text {iv }}$ conceitua como princípios da educação das escolas quatro elementos:

\begin{abstract}
... o desenvolvimento do meio; a formação integral; a Pedagogia da Alternância; e o Associativismo Local. Essa proposta é centrada no associativismo local, em que agricultores e agricultoras, pais e mães de estudantes e outros membros da comunidade se unem para formar uma associação que será a responsável pela implementação e administração da EFA.
\end{abstract}

O diagnóstico torna-se um diferencial nessa forma de fazer escola no campo, pois não só aproxima a comunidade da escola, como permite que o material didático seja utilizado em favor dos interesses da comunidade em que a escola existe e dentro da realidade do aluno.

Sobre a alternância, significa que o aluno, dentro da realidade levantada, oportuniza uma escola em que existirá um "tempo escola" e um "tempo comunidade", e dentro do diagnóstico levantado, os alunos realizarão aprendizagens em saberes que enriqueçam o conhecimento científico que interessa à sua comunidade, 
sendo posteriormente repassados para a comunidade nas atividades programadas no tempo comunidade.

O modelo de alternância das EFAs para Ribeiro (2010),

... articulam o trabalho produtivo com a educação escolar; avançam em relação aos estágios curriculares feitos em parceria entre escolas e empresas; fortalecem a identidade pessoal e comunitária dos agricultores e estimulam a participação política dos jovens. Colocam a mudança social nas relações pessoais, democracia na participação política e a cidadania na autonomia do agricultor que vive do seu trabalho. $\mathrm{O}$ projeto pedagógico e social das CFRs e das EFAs será centrado na pessoa humana, em sua liberdade de escolha e de busca da autonomia através do trabalho. (p. 381).

A aprendizagem nas EFAs apresenta, como toda educação, finalidades. Dessas finalidades destacamos a formação integral do aluno, que acontece com o acompanhamento do professor/tutor nas disciplinas comuns do currículo, com o aproveitamento de atividades que incentivam a convivência, o desenvolvimento de tarefas, a reflexão e o desenvolvimento do meio, centrado na valorização do campo como instrumento capaz de reproduzir vida com qualidade e dignidade, sempre com o intuito da emancipação política, social, cultural do homem e da mulher campesina. É o que defende a organização UNEFAB no seu Website.

A União Nacional das Escolas Família Agrícola do Brasil - UNEFAB foi criada em 1982, por meio de um processo de discussão e estudo realizado pelas EFAs - Escolas Famílias Agrícolas - como instituição de representação e assessoria pedagógica e administrativa, objetivando promover o intercâmbio e divulgação dos trabalhos, acompanhando o processo de formação dos monitores (professores das EFAs) e de seus dirigentes, com o intuito de também estabelecer parcerias e outras formas de cooperação técnico-financeira.

A UNEFAB explica que, a partir da década de 70, ocorreu rápida expansão desse modelo para outros 22 estados brasileiros e que, atualmente, existem 145 EFAs em funcionamento e outras dezenas em implantação, beneficiando cerca de 13.000 alunos e 70.000 agricultores, nas quais trabalham diretamente 850 monitores. Essas escolas já formaram mais de 50.000 jovens, dos quais mais de $65 \%$ permanecem no meio rural, desenvolvendo seu próprio empreendimento junto às suas famílias ou exercendo vários tipos de profissões e lideranças.

A experiência das EFAs demonstra que os movimentos sociais têm conseguido derrubar barreiras, mesmo quando os gestores nas esferas municipais e estaduais 
não contribuem com uma política de educação, pela forma de organização que empreendem. Batista (2012) explica:

Assim, os movimentos sociais com a resistência e persistência que lhes são peculiares têm, a partir da mobilização popular, da articulação dos setores populares organizados da sociedade reivindicar, afirmar, sistematizar e exigir que o estado programe projetos educacionais identificados com as ideias $\mathrm{e}$ concepções por eles produzidas. Eles estão derrubando as cercas das cidades universitárias, as cercas dos conhecimentos, conquistando cidadania e fazendo uma educação identificada com os anseios das classes populares, com o perfil por eles delineado. Uma educação Popular com os pés fincados na terra, com a cara dos sujeitos da terra. (p. 16).

O crescente número de assentamentos implantados no Brasil nas últimas décadas demonstra a necessidade dos movimentos populares se articularem e se organizarem para produzir uma educação que resignifique, sobretudo, o ideal do campesinato, sua importância para o homem e mulher da cidade, que contribua com a permanência dos campesinos em áreas rurais.

\section{Breve apanhado da formação dos Assentamentos Rurais em Sidrolândia - MS}

Os contornos do agrário no Município de Sidrolândia apresentam as mesmas características da formação agrária do território brasileiro, marcado pela concentração de terra em mãos de poucos, pela monocultura e bovinocultura, destacando-se o fato de que desde o fim da Guerra do Paraguai (1864 - 1870), o governo brasileiro distribuiu terras para fazendeiros da Região Sudeste e também a empresas estrangeiras, para promover a ocupação desse espaço geográfico, ainda em disputa com o Paraguai.

Essa dominação da terra também contou com a contribuição e o uso da força de grupos armados, para o qual os coronéis possuíam bandos que garantiam o domínio das terras e expropriação de outras, com a expulsão do campo, inclusive de pequenos agricultores que viviam em parcelas que eram anexadas às grandes fazendas. Esse período ficou caracterizado como aquele que imperava na região: a "Lei do 44", em menção ao revólver 44, principal instrumento utilizado pelo banditismo que se alastrava por todas as regiões do antigo sul do Mato Grosso, conforme afirmado por Corrêa (2009).

A presença de terras férteis, como na região do Vale do Vacaria, formada da decomposição de rochas basálticas ricas em nutrientes como o ferro, incentivou a chegada de uma categoria de colonos, nos anos 30 do século XIX, composta de imigrantes paulistas e mineiros. Foi nesse 
período que chegou à região, Sidrônio Antunes de Almeida.

Sidrônio foi quem ofereceu partes de sua propriedade para formar uma vila no entorno da estação ferroviária, onde posteriormente se formou o núcleo urbano da cidade de Sidrolândia, que levou consequentemente esse nome como forma de homenagem àquele que é considerado um dos fundadores do município.

A ocupação das terras da região também passou pela distribuição de grandes áreas a empresas estrangeirais pelo governo federal; por exemplo, o espaço onde hoje estão organizados os assentamentos Alambari, Eldorado, Capão Bonito e Vacarias foi destinado à companhia norte-americana Brazil Land Cattleand Packing Co., constituindo uma área total de 158.873 hectares, sendo incorporada ao patrimônio da União no ano de 1940, com o Decreto Lei ${ }^{\circ} 2.436$, de julho de 1940, que desapropriou terras sob o domínio de empresas estrangeiras.

Em 1950, essas terras foram repassadas para a Sociedade Anônima Cafeeira do Noroeste que aos poucos foi se desfazendo da área ou arrendando, inclusive, ao latifundiário Lúdio Coelho, restando uma área remanescente de 14.015 hectares que ficou em propriedade de Paulo Eduardo Souza Firmo, latifundiário paulista.
Da ocupação inicial do território de Sidrolândia aos dias atuais, ressalta-se também a vinda de muitos colonos gaúchos na década de 70 do século passado, também com incentivos do Governo Federal, que compraram grandes porções de terra e passaram a desenvolver uma intensa produção agrícola, baseada na soja e no milho, plantadas em grandes áreas de terras.

Os fazendeiros mais tradicionais continuaram a desenvolver a pecuária de corte no modelo tradicional, extensivo, utilizando-se, para tanto, também de grandes porções de terra, onde o gado é criado à solta, sem muita preocupação, utilizando-se de pouca mão de obra.

Há dez anos, aproximadamente, tendo em vista a decadência da bovinocultura extensiva no município e, conjuntamente com incentivos governamentais para interiorização da industrialização e desenvolvimento do Mato Grosso do Sul, iniciou-se a plantação de cana-de-açúcar para produção de açúcar e álcool.

Esse novo modelo de produção (sucroalcooleira) não significou mudança em relação à concentração fundiária, ao monopólio das terras e do poder político na cidade, administrada até os dias de hoje por representantes vinculados às oligarquias agrárias. 
$\mathrm{O}$ processo de formação dos assentamentos rurais de Sidrolândia teve início após a queda do regime militar com a redemocratização do país, a reorganização dos movimentos sociais e surgimento do Movimento Sem Terra (1985) - e a criação do Instituto de Colonização e Reforma Agrária - INCRA (1984).

A luta pela democratização das terras em Sidrolândia iniciou-se em 1984, tendo como um dos articuladores o Sindicato dos Trabalhadores Rurais - STR, que lutava pela implementação de um assentamento nas terras da companhia cafeeira, que anteriormente pertenceu à Brazil Land Cattleand Packing Co., consideradas improdutivas. A companhia cafeeira, com medo do processo de desapropriação para a reforma agrária, arrendou a área para um dos maiores latifundiários do Estado, Lúdio Coelho. Depois de diversas ocupações pelos sem terra e ações policiais para retirar os trabalhadores, em 6 de abril de 1989 houve a desapropriação de 2.705 hectares, onde foram assentadas 132 famílias, dando origem ao assentamento Capão Bonito I.

Tendo em vista essa primeira conquista (porteira do latifúndio aberta), o STR, com o apoio da Federação dos Trabalhadores na Agricultura (FETAGRI), do MST e de várias famílias acampadas, conseguiu a desapropriação do restante da fazenda em 1997, formando o assentamento Capão Bonito II, onde foram beneficiadas outras 320 famílias, e do Assentamento São Pedro, com outras 295 famílias.

A partir dessa e de outras lutas empreendidas, envolvendo outras entidades de organização de movimentos sociais, como a Central Única dos Trabalhadores - CUT Rural, o latifúndio da antiga fazenda Brazil Land Cattleand Packing Co., foi-se desfazendo, sendo constituídos outros assentamentos: Jibóia, Vacaria e, fora da área da fazenda americana, o Assentamento Santa Terezinha.

Entre o período de 1999 e 2004 houve a criação dos assentamentos Vista Alegre, Terra Solidária I e II com recursos do Banco da Terra ${ }^{\mathrm{v}}$.

De 2006 a 2010 foram implantados novos projetos nas terras remanescentes da fazenda Brazil Land Cattleand Packing $\mathrm{Co}$, as quais naquela ocasião estavam sob a propriedade do latifundiário Paulo Eduardo Souza Firmo, sendo constituídos os assentamentos Eldorado, Eldorado I Che Guevara, Eldorado Parte, Alambari's FAF e CUT. Finalmente em 2010 foi assentado o último grupo de famílias na região, formando o Assentamento Nazareth, na 
divisa com os municípios de Campo

Grande e Nova Alvorada do Sul ${ }^{\mathrm{vi}}$.
O quadro 1 apresenta uma síntese do processo de crescimento dos assentamentos em Sidrolândia.

Quadro 1 - Sidrolândia - MS: Assentamentos de Reforma Agrária.

\begin{tabular}{|c|c|c|c|c|}
\hline Ordem & Assentamento & $\begin{array}{l}\text { Ano } \\
\text { assentamento }\end{array}$ & $\begin{array}{ll}\text { do Área } & \text { em } \\
\text { lectares } & \end{array}$ & Número de lotes \\
\hline 01 & Capão Bonito & $20 / 10 / 1989$ & $2.585,40$ & 133 \\
\hline 02 & Capão Bonito II & $14 / 10 / 1997$ & $8.231,50$ & 308 \\
\hline 03 & São Pedro & 23/12/1998 & $8.592,23$ & 296 \\
\hline 04 & Vista Alegre & $10 / 11 / 1999$ & $1.030,82$ & 50 \\
\hline 05 & Vacaria & $27 / 03 / 2000$ & $1.049,15$ & 48 \\
\hline 06 & Jibóia & $11 / 07 / 2000$ & $7.218,70$ & 238 \\
\hline 07 & Capão Bonito III & $27 / 12 / 2000$ & 600 & 23 \\
\hline 08 & Geraldo Garcia & $29 / 12 / 2000$ & $5.775,21$ & 182 \\
\hline 09 & Santa Terezinha & $13 / 08 / 2001$ & $1.537,91$ & 64 \\
\hline $\begin{array}{l}10 \\
11 \\
12\end{array}$ & $\begin{array}{l}\text { Complexo Alambari: Alambari FAF; } \\
\text { Alambari CUT; Alambari FETAGRI }^{\text {vii }}\end{array}$ & $27 / 12 / 2005$ & $8.206,71$ & 589 \\
\hline 13 & Eldorado II & $27 / 12 / 2005$ & $9.619,89$ & 777 \\
\hline $\begin{array}{l}14, \\
15,16\end{array}$ & $\begin{array}{l}\text { Complexo Eldorado I: João Batista; } \\
\text { Che Guevara; APAGE }\end{array}$ & $27 / 12 / 2005$ & $9.972,12$ & 640 \\
\hline 17 & Eldorado Parte & $07 / 12 / 2007$ & 700 & 70 \\
\hline 18 & Terra Solidária & $28 / 11 / 2003$ & 360,0218 & 11 \\
\hline 19 & Terra Solidária II & $19 / 10 / 2004$ & 607,4458 & 20 \\
\hline 20 & Valinhos & $*$ & $*$ & 75 \\
\hline 21 & Mutum & $*$ & * & 69 \\
\hline 22 & Barra Nova I e II & $27 / 12 / 2005$ & $3.940,42$ & 268 \\
\hline 23 & Altemir Tortelli (Estrela) & $27 / 12 / 2015$ & $1.489,99$ & 114 \\
\hline 24 & Santa Lúcia & $09 / 3 / 2007$ & $1.322,29$ & 100 \\
\hline 25 & Nazareth & $27 / 7 / 2014$ & $2.298,24$ & 171 \\
\hline \multicolumn{2}{|c|}{ Total de Assentamentos: 25} & a. 75.138,04 & \multicolumn{2}{|c|}{ Total de Lotes 4.246} \\
\hline
\end{tabular}

(*) Sem Informação.

Fonte: INCRA, Ouvidoria Agrária do Estado de Mato Grosso do Sul, 2016.

Org.: Adenilso Assunção.

A organização e luta dos movimentos sociais no Estado de Mato Grosso do Sul representou conquistas importantes para a reforma agrária e transformou o município, havendo expressivo número de assentados e acampados, segundo o Instituto Nacional da Reforma Agrária - INCRA.
Sidrolândia, $\quad$ pelos

dados evolutivos/comparativos dos Censos Demográficos do IBGE, apresenta um crescimento demográfico expressivo desde a implantação dos assentamentos em sua área rural, sendo que no Censo 2010 apresentava um total de 42.132 habitantes, dos quais $34 \%$ residentes no campo. Percebe-se um crescimento demográfico 
significativo com relação ao final do século passado, quando a população total registrava 23.483 habitantes (Quadro 2).

Com a nova realidade representada pela política de implantação dos assentamentos, ampliou-se também expressivamente a demanda por políticas públicas no campo, entre as quais, destacou-se a Educação.

Quadro 2 - Sidrolândia - MS: População 1991 - 2010.

\begin{tabular}{|c|c|c|c|}
\hline Ano do Censo & População Urbana & População Rural & População Total \\
\hline 1991 & 10.794 & 5.546 & 16.340 \\
\hline 2000 & 15.862 & 7.621 & 23.483 \\
\hline 2010 & 27.783 & 14.349 & 42.132 \\
\hline
\end{tabular}

Fonte: IBGE - Censos Demográficos de 1991, 2000 e 2010.

Organização: Adenilso Assunção.

No Censo Agropecuário de 2006 Sidrolândia apresentou 2.205 estabelecimentos agropecuários com até 10 ha. Após a implantação dos novos assentamentos nos anos de 2007 e 2008 no município, todos os lotes com área de até 10 hectares, este número mais que dobrou, chegando a mais de quatro mil assentados com os projetos de assentamento Eldorado II, Eldorado I, Alambari(s) FAF, CUT, FETAGRI, Estrela, Santa Lúcia, Eldorado Parte e Nazareth.

O Superintendente Regional do Instituto de Colonização e Reforma Agrária - INCRA no Mato Grosso do Sul, estima que pequenos agricultores e assentados em Sidrolândia ultrapassem a seis mil famílias em áreas individuais de até 10 hectares.

Essa realidade também tem levado a confrontos pela ocupação dos espaços de poder local, tradicionalmente ocupados por latifundiários. O cenário apresenta hoje novos atores e uma disputa por projetos políticos e políticas públicas diferenciadas, provocando a mobilização de parcela da sociedade, no sentido de garantir maiores avanços nos direitos e cidadania para uma parcela à margem dos espaços de decisão do município.

Nessa conjuntura política e social, os movimentos sociais e assentados convivem com uma realidade de grandes dificuldades, imperando a falta de recursos públicos, de políticas públicas e estrutura social, além de enfrentar desafios, tais como as diferenças internas entre os assentamentos/assentados e no interior dos próprios movimentos sociais, dada à existência de divisões em grupos de assentados e organizações distintas, como também a diversidade de origens dos assentados (incluindo alguns de outras nacionalidades). 
É com essa realidade e pluralidade que se organiza a escola pública nas áreas rurais de Sidrolândia, sendo que seu papel deveria ser o de também contribuir com a formação deste território. Nesse contexto, a criação da Escola Família Agrícola de Sidrolândia (EFASIDRO) representa e se coloca como instrumento que se contrapõe, inclusive, à educação que acontece nas escolas públicas do campo, atendendo exclusivamente filhos de assentados da região, com uma proposta educacional diferenciada.

\section{Escola Família Agrícola de Sidrolândia e a sua importância na formação dos camponeses}

São inúmeras as dificuldades existentes no funcionamento das escolas em áreas de assentamentos rurais em Sidrolândia, muitas estão instaladas em locais longínquos, demandando viagens longas (de até quatro horas no total) nos veículos escolares para crianças e adolescentes, além de muitas das escolas funcionarem em condições precárias, espécie de "puxadinho" das escolas da cidade, com proposta educacional inadequada aos filhos dos campesinos.

Sobre a prática de escolas no campo desenvolverem atividades análogas às oferecidas nas escolas da cidade, Arroyo (2007) afirma que o campo é visto como uma extensão, como um "quintal da cidade". Tal prática ocorre também em outros tipos de serviços profissionais, como os de médicos e enfermeiras, com seus serviços adaptados, muitas vezes precarizados, oferecidos às populações do campo.

Tal situação representou um incentivo para as famílias campesinas a se organizarem e trazer para Sidrolândia a experiência da Escola Família Agrícola.

Localizada no Assentamento Capão Bonito II, próximo à Rodovia MS 455, estrada da Gameleira, a Escola Família Agrícola de Sidrolânda - EFASIDRO recebeu sua autorização de funcionamento, em 2006, do Conselho Estadual de Educação, para o $6^{\circ}$ ao $9^{\circ}$ ano do Ensino Fundamental, depois de mobilizações da comunidade assentada. Essa autorização foi renovada no ano de 2012 por um período de cinco anos, que vencerá em 2017. Segundo a direção da EFASIDRO existe um trabalho junto a Supervisão de Ensino do Estado que atua em Sidrolândia para sua renovação.

No ano de 2016, a escola atendeu 67 alunos com idades entre 10 e 17 anos, nos anos autorizados pelo Conselho Estadual de Educação, sendo que os estudantes vêm de 24 dos assentamentos de Sidrolândia e somente um aluno vem do Município de Terenos. 
Desde o início de seu funcionamento a EFASIDRO já recebe como legado os mais de quarenta anos de atividade da Pedagogia da Alternância no Brasil, em cuja experiência registra-se milhares de jovens formados pelas EFAs e pelas Casas Familiares Rurais, em dezenas de estados do país.

Sobre o projeto das Escolas Famílias Agrícolas, Foreste e Jesus (2011, p. 3) afirmam: “... constituiu um projeto de educação que valoriza o campo, que empreende junto aos alunos projetos profissionais voltados para essa realidade e que desenvolve suas ações na busca pela dignidade da vida do homem do campo".

O elemento estruturante que faz com que essa escola se diferencie na educação no meio rural encontra-se no fato de articular a realidade vivida pelos educandos com a prática agrícola e a teoria científica. Tal experiência rompe com uma concepção não construtiva, que tem a escola como a única ou maior responsável pela educação das pessoas, sem levar em conta a família, a comunidade e as relações socioculturais que as pessoas estabelecem com seu meio, educando tanto quanto a escola.

Outro fator diferenciador na experiência da EFASIDRO está em seus funcionários, pois os doze professores, dois técnicos agrícolas e uma secretária são provenientes de áreas rurais, assentamentos, propiciando que estes se insiram no contexto social das comunidades, o que facilita a interlocução com as famílias para participarem do processo de ensino e aprendizagem. A maioria dos professores é oriunda de universidades públicas, os quais possuem cursos com formação específica em educação do campo, nas áreas de ciência da natureza, ciências humanas e exatas.

A direção da EFASIDRO estimula e prefere 0 trabalho pedagógico desenvolvido por professores recémformados, pois os considera mais propensos a trabalharem uma educação diferenciada.

Pelas características que apresenta, professores com formação, prioritariamente, na área de educação do campo e uma pedagogia voltada para essa realidade específica, a EFASIDRO tornase imprescindível como alternativa ao jovem do campo, bem como para suas famílias. É importante ressaltar que tais condições contribuem para a diminuição da migração rural que compromete a produção e a sucessão familiar, pois muitos jovens já saem do campo para estudar, muitos dos quais com idade entre 13 ou 14 anos.

A Escola Família Agrícola de Sidrolândia trabalha respeitando os quatro 
pilares de organicidade da Pedagogia da Alternância, por meio dos seus instrumentos pedagógicos e seus pressupostos teóricos e metodológicos formulados em mais de quatro décadas de pesquisas científicas.

Os estudantes são divididos em grupos para o desenvolvimento de trabalhos diários, como organização e limpeza do espaço físico coletivo, cuidados diários com a horta orgânica, visitas aos sitiantes da região, entre outros. Individualmente, cada um é responsável pela organização e limpeza de seu quarto, ambiente de estudo, utensílios e ferramentas disponibilizadas. Utilizam-se de instrumentos pedagógicos diversos, como caderno de alternância, plano de estudos e projetos de pesquisa.

O currículo é organizado de forma dinâmica e integral, havendo interdisciplinaridade dos componentes curriculares do eixo comum em conjunto com as aulas técnicas: agricultura, zootecnia e práticas agrícolas.

A escola articula-se com a Empresa Brasileira de Pesquisa Agropecuária EMBRAPA, a Agência de Desenvolvimento Agrário e Extensão Rural - AGRAER, o Movimento Sem Terra - MST, a Federação dos Trabalhadores em Agricultura - FETAGRI e a Central Única dos Trabalhadores - CUT e estabelece parcerias com os sitiantes da região, que oportunizam aos alunos receberem aulas práticas dos técnicos agrícolas, de piqueteamento ${ }^{\mathrm{ix}}$, agroindústria de polpa e frutas, desenvolvimento de hortas, adubos orgânicos, irrigação, viveiros de mudas do cerrado, entre outros. Para o ano de 2017 estão estabelecendo parceria com a Universidade Federal da Grande Dourados - UFGD, para que possam contribuir com a formação de seu quadro de professores, em termos dos conhecimentos técnicos e pesquisa.

A Universidade Federal da Grande Dourados também está contribuindo na construção de uma proposta para o Ensino Médio para a escola, sendo que há mais de dois anos a direção da EFASIDRO vem tentando, no Governo do Estado, autorização para esta oferta, o que vem sendo dificultado pela falta de infraestrutura física da escola, segundo o Supervisor do Estado. A parceria com a UFGD também disponibilizará à EFASIDRO a sede do Assentamento Eldorado, onde hoje funciona um centro de pesquisa da universidade, que poderá utilizar o espaço para salas de aulas.

Aproximando a EFASIDRO das ideias já colocadas neste artigo, sobre nossa defesa da educação popular, Begnami (2011) defende que: 
... as CEFFAs e a Educação do Campo não se limitam à escola. Assumem uma dimensão de educação popular, de educação formal, /mas também informal ao envolver a família e a comunidade em contextos de participação e processos de formação formalizados e fomentados pelo movimento. Ambas nascem como uma crítica e, ao mesmo tempo, uma proposta concreta de educação apropriada à realidade do campo. (p. 4).

A escola é uma demonstração de que é possível para os movimentos populares do campo organizarem-se e tornarem-se atores de suas próprias experiências, sobretudo, para que a educação assuma compromissos emancipatórios e de formação crítica de seus educandos, conscientes de seu papel na sociedade.

Atualmente, o funcionamento da escola ocorre a partir de convênios estabelecidos entre a EFASIDRO e a Secretaria Municipal de Educação de Sidrolândia, cujo compromisso é repassar anualmente o valor de $\mathrm{R} \$ 3.700,00$ (três mil e setecentos reais) por aluno. Entretanto, segundo nos informou a direção, o repasse encontra-se atrasado desde dezembro de 2015. Outro convênio foi feito com a Secretaria Estadual de Educação, envolvendo o pagamento de uma das professoras efetivas que trabalha em regime de 40 horas semanais.

$\mathrm{O}$ recebimento e gerenciamento dos recursos acontecem a partir da Associação de Pais da Escola Família Agrícola de Sidrolândia, sendo a gestão coletiva. A direção da escola é escolhida pelos pais, professores e estudantes.

$\mathrm{O}$ não repasse pelo Município de Sidrolândia dos valores relativos ao convênio no ano de 2015 e 2016 provocou o atraso dos salários dos professores contratados pela EFASIDRO no município. Segundo a direção da escola, a relação com o poder local é difícil, havendo desrespeito com a educação do campo. Isso teve como consequência a organização de manifestações de pais, alunos e professores da EFASIDRO em frente à sede administrativa do município, conforme noticiado no jornal Região News ${ }^{\mathrm{x}}$.

A forma como o Estado (Governo Federal, Estados e Municípios) vem tratando os movimentos, criminalizandoos, demonstra um novo momento a ser enfrentado pelas organizações populares, pois, muito além do não repasse dos valores estabelecidos nos convênios, há casos de perseguição e até prisões de muitas lideranças ${ }^{\mathrm{xi}}$.

$\mathrm{Na}$ direção da Escola Família Agrícola de Sidrolândia, o professor César Junior da Silva, formado em Letras, classifica a relação entre a escola e a Prefeitura do município como muito difícil. Atualmente, a gestão atual do 
PSDB não estabelece condições de diálogo com a escola, tampouco com a comunidade rural, nem apoia as demandas dos assentamentos, questionando, inclusive, a existência de uma escola de cunho popular. Afirma o professor César que o prefeito tem dificuldade, sobretudo, em aceitar que os assentados estudem, pois considera que a enxada é a caneta que o assentado deveria adotar.

César Junior acredita na construção de uma nova conjuntura para o município em 2017, a partir da renovação no quadro de vereadores com a posse, inclusive, de um representante de assentamento e do novo prefeito municipal.

O professor afirmou que até julho de 2016, possuía uma ótima articulação com o Governo Federal por meio do Ministério da Educação - Secretaria de Educação Continuada, Alfabetização, Diversidade e Inclusão (SECADI); porém, com o afastamento da Presidenta Dilma e a subida ao poder de Michel Temer, essa Secretaria teve desarticulada sua atuação junto aos movimentos sociais, desestabilizando as relações e findando as políticas com os diversos segmentos minoritários da sociedade que ali se sentiam representados.

Como mecanismo de fortalecimento da prática educacional, a escola possui articulação nacional com a UNEFAB e contribui com a articulação de uma Associação Estadual das EFAS do CentroOeste, sendo que pela distância entre os estados e as escolas, discute-se a organização de uma associação que atue nos estados de Mato Grosso e Mato Grosso do Sul.

A EFASIDRO e outras 177 instituições educacionais brasileiras, entre organizações não governamentais, escolas públicas e particulares, foram reconhecidas pelo Ministério da Educação como exemplos de inovação e criatividade na educação básica através do prêmio Experiência Educacional Inovadora e Criativa.

O prêmio, oferecido pelo MEC em dezembro de 2015, identifica e reconhece iniciativas que contribuem para a melhoria da qualidade da educação brasileira, reconhecendo a EFASIDRO como uma escola comunitária que contribui nesse quesito.

A EFASIDRO vem trilhando um caminho próprio, com contornos e componentes que se aproximam de diversas tendências do pensamento pedagógico moderno, baseado nos paradigmas emancipadores. Daí sua grande importância social e territorial.

\section{Considerações finais}


É fato já reconhecido que o Estado oferece uma educação precária para a população campesina ou descontextualizado da realidade por ela vivenciada e muito aquém daquela cobrada pelos movimentos sociais do campo. Assim, nossa intenção ao final desta pesquisa foi evidenciar e defender a importância e a necessidade de uma educação popular para a população brasileira, particularmente, para a camponesa.

Dessa forma, defendemos a necessidade de avançarmos, a partir das iniciativas propostas pelos movimentos sociais que reivindicam, sobretudo, uma educação com características libertárias, pois, caso contrário, dificilmente construiremos um modelo de educação pública com as características necessárias para a emancipação da classe trabalhadora.

Nessa perspectiva, a educação oferecida pelas EFAs, cunhada na educação popular, ou seja, vinculada à população a que se destina, observando e valorizando as trocas de experiências, a importância da família, os saberes populares e, ao mesmo tempo, garantindo uma educação científica pelos seus professores e técnicos, promovendo a geração de renda, o fortalecimento da agricultura camponesa e as relações comunitárias através da solidariedade, é uma experiência que deve ser reconhecida e disseminada.

Consideramos que a EFASIDRO se constitui numa alternativa promissora para os jovens e famílias de agricultores e moradores do campo de Sidrolândia e região, pois leva em conta o contexto social, histórico e espacial em que estão inseridos os alunos, compreendendo que o desenvolvimento do campo passa também pela construção e consolidação de um projeto de educação como instrumento de conscientização crítica de seus educandos.

Dessa forma, ainda que estejamos vivendo uma conjuntura política fortemente conservadora e que sinaliza inúmeras perdas para as classes populares, é preciso resistir e lutar pela propagação de experiências como a oferecida na EFASIDRO.

Portanto, enfatizamos a necessidade de construção e ampliação de escolas que mantêm nos seus preceitos e organização a experiência democrática, não somente referente à eleição para diretores, mas no seu processo de direção como um todo, envolvendo: a discussão de sua proposta pedagógica; a relação estreita com a comunidade onde está inserida espacialmente e, fundamentalmente, que contribua com a emancipação social e política da classe trabalhadora, 
promovendo, necessariamente, uma educação libertadora.

\section{Referências}

Almeida Pinto, M. P., \& Germani, G. I. (2013). O território da Educação do Campo: as Escolas Família Agrícola. GeografAR, Recuperado em 6 de junho de 2016, de https://geografar.ufba.br/sites/geografar.uf ba.br/files/geografar_almeidapintogermani territorioeducacaocampo.pdf.

Arroyo, M. G., \& Fernandes, B. M. (1999). A educação básica e o movimento social do campo. Articulação Nacional por Uma Educação do Campo, 8.

Arroyo, M. G. (2007). Políticas de formação de educadores(as) do campo. Cadernos CEDES, 27(72), 16.

Batista, M. S. X. (2007). Os movimentos sociais cultivando uma educação popular do campo. ANPED, 2007, 16. Recuperado em 21 de setembro de 2015 de http://www.anped.org.br/sites/default/files/ gt06-3377-int.pdf.

Begnami, M. J. F. (2011). Os CEFFAs e a educação do campo. In Revista da Formação por Alternância. Educação do Campo. Brasília: UNEFAB.

Bezerra, M. C. S., \& Bezerra Neto, L. (2007). Aspectos da educação rural no Brasil, frente aos desafios educacionais propostos pelo MST. Revista HISTEDBR on-line. (23).

Bezerra Neto, L. (2010). Educação do campo ou educação no campo? Revista HISTEDBR On-line, (152). Recuperado em 10 de Junho de 2016 de http://www.histedbr.fae.unicamp.br/revista ledicoes/38/index.html.
Brandão, C. R., \& Bezerra, A. (1987). A questão política da educação popular. São Paulo: Brasiliense.

Brasil. (1996). LDB - Lei $n^{\circ} 9394$, de 20 de dezembro de 1996. Estabelece as diretrizes e Bases da Educação Nacional. Brasília: MEC.

. Conselho Nacional de Educação. (2002) Resolução n. 01. Brasília: CNE.

Caldart, R. S. (1997). Educação em movimento: formação de educadoras $e$ educadores no MST. Petrópolis, Vozes.

(2002). Pedagogia do Movimento Sem Terra: escola é mais do que escola. Petrópolis, RJ: Vozes.

Camacho, R. S. (2011). A Geografia no contexto da educação do campo: construindo o conhecimento geográfico com os movimentos camponeses. Revista Percurso, 3(2), 25. Recuperado em 06 de agosto de 2016 de http://periodicos.uem.br/ojs/index.php/Perc urso/article/view/13847.

Corrêa, V. B. (2009). História e violência cotidiana de um "povo armado". Projeto História, São Paulo, (39), 66.

Escolas Famílias Agrícolas da Zona da Mata de Minas Gerais - AMEFA. Recuperado em 03 de agosto de 2016 de https://amefa.wordpress.com/.

Fernandes, B. M. (1998). Gênese e Desenvolvimento do MST. Caderno de Formação, (30). São Paulo: Editora Perez.

(2002) Diretrizes de uma caminhada. In Kolling, E. J., Cerioli, P. R., \& Caldart, R. S. Por uma educação do campo. (p. 89-101). Brasília, DF: Articulação Nacional Por Uma Educação do Campo. Coleção Por Uma educação do Campo. 
Foreste, E., \& Jesus, J. G. (2011). Escolas Famílias Agrícolas: um projeto de Educação específico do Campo. Recuperado em 12 de Setembro de 2015 em

web2.ufes.br/educacaodocampo/down/cdro m1/ii_11.html.

Freire, P. (2011). Pedagogia da autonomia: saberes necessários à prática educativa. São Paulo: Paz e Terra, 2011.

Gadotti, M. (2014). 50 anos depois: como reverter o golpe na Educação Popular. UniFreire.

Leite, S. C. (2002). Escola rural: urbanização e políticas educacionais. São Paulo: Cortez.

Moreira, A. F., \& Silva, T. T. (2005). Currículo cultura e sociedade. São Paulo: Cortez.

Oliveira, F. (2003). A economia brasileira: crítica à razão dualista. São Paulo: Boitempo Editorial.

(2013). O Estado e o urbano no Brasil. CEBIS. Cadernos de Debate, Rio de Janeiro, 16.

Oliveira, A. U. (2007). $O$ modo de produção capitalista e a reforma agrária. São Paulo: Labur Edições FFLCH.

Pessoti, A. L. (1978). A Escola Família Agrícola: Uma alternativa para o ensino rural. (Dissertação de Mestrado). Fundação Getúlio Vargas.

\footnotetext{
${ }^{\mathrm{i}}$ Mais sobre o assunto em Ariovaldo Umbelino de Oliveira, O Modo de Produção Capitalista, Agricultura e Reforma Agrária. Disponível em: <http://www.geografia.fflch.usp.br/graduacao/apoio /Apoio/Apoio_Valeria/Pdf/Livro_ari.pdf $>$ Acesso em: 26 de agosto de 2016.
}

Queiroz, J. B. P. (2004). Construção das Escolas Famílias Agrícolas no Brasil: ensino médio e educação profissional. (Dissertação de Doutorado). Universidade de Brasília.

Ribeiro, M. (2010). Movimento camponês, trabalho e educação. Liberdade, autonomia e emancipação: princípios/fins da formação humana. São Paulo: Expressão Popular.

Saviani, D. (2007). História das ideias pedagógicas no Brasil. São Paulo: Saraiva.

Silva, T. T. (1996). Identidades terminais: as transformações na política da pedagogia e na pedagogia da política. Petrópolis: Vozes.

União Nacional das Escolas Famílias Agrícolas do Brasil - UNEFAB (http://www.unefab.org.br)

Thomaz Júnior, A. (2010). Povoando o território da luta pela terra e pela reforma agrária no Brasil contemporâneo. Revista Pegada Eletrônica, 11(2), 31. Recuperado de:

$<$ http://revista.fct.unesp.br/index.php/pega da/article/viewFile/1303/1299>. Acesso em: 28/10/2016.

Wanderley, L. E. W. (1991). Participação popular: poder local e conselhos. São Paulo em Perspectiva. São Paulo: Fundação SEADE.

\footnotetext{
${ }^{i i}$ Mais informações sobre a história da educação e a importância desses educadores brasileiros no processo de construção da educação que temos hoje podem ser observadas em Saviani (2007).

iii O professor Fernando de Araújo Penna - UFF, em entrevista ao portal da ANPED, afirma que esse movimento existe desde 2004, mas que ganhou força em 2016. Entre as propostas desse grupo, existem, além da defesa de uma escola
} 
descontextualizada, outras pautas conservadoras. Maiores informações sobre o tema em: http://www.anped.org.br/news/entrevista-com-

fernando-de-araujo-penna-escola-sem-partido-serieconquistas-em-risco.

iv Maiores informações disponível em: https://amefa.wordpress.com.

${ }^{v} \mathrm{O}$ Banco da Terra foi uma política elaborada pelo governo F. H. C., tendo como base a Lei Complementar $n^{\circ} 93$ de 04/02/1998, regulamentada pelo Decreto $\mathrm{n}^{\mathrm{o}} 3.027 / 99$, posteriormente transformada em Programa Nacional de Crédito Fundiário no governo Lula, cuja criação era destinada ao financiamento do acesso a terra, bem como aos investimentos em infraestrutura básica a trabalhadores rurais sem-terra, jovens rurais, minifundiários, arrendatários, meeiros e posseiros. Recebeu fortes críticas dos movimentos sociais dada a lógica mercantil explicitada nessa política. Ver, entre outros, Thomaz Junior (2010).

vi Ressaltamos que ainda existem muitos acampamentos em luta pela terra no município e nos municípios vizinhos.

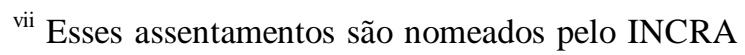
somente de Alambari. No entanto, considerada as diferentes formas de organização dos assentados, em que cada grupo articula-se por entidades e associações distintas e apresentam origens diferentes, optamos por dividi-los, conforme melhor organização compreendida pelos grupos que estão dispostos na terra.

viii Este caso é idêntico ao referido anteriormente.

${ }^{\text {ix }}$ Ato de dividir a parcela rural em várias pequenas partes, como o objetivo de melhor trabalhar do manejo do gado nesses pedaços.

x Professor da EFASIDRO traz crianças para pressionar prefeitura a reativar convênio. Disponível em: <http://www.regiaonews.com.br/noticias/207945/--professor-da-efasidro-traz-criancas-para-

pressionar-prefeitura-a-reativar-convenio----.html>. Acesso em: 15 de outubro de 2016.

${ }^{\mathrm{xi}}$ Mais sobre a questão de prisões indiscriminadas de lideranças sem terra disponível em <www.brasil247.com/pt/247/.../MST-condenaprisão-de-líder-sem-terra-no-RS.htm>. Acesso em: 26 de agosto de 2016.
Recebido em: 05/02/2017

Aprovado em: 12/03/2017

Publicado em: 19/04/2017
Como citar este artigo / How to cite this article / Como citar este artículo:

APA:

Assunção, A. S., \& Bernardelli, M. L. F. H. (2017). Educação popular e educação do/no campo: perspectivas para uma educação inclusiva - a Escola Família Agrícola em Sidrolândia - MS. Rev. Bras. Educ. Camp., 2(1), 294-322. DOI: http://dx.doi.org/10.20873/uft.2525$\underline{4863.2017 \mathrm{v} 2 \mathrm{n} 1 \mathrm{p} 294}$

ABNT:

ASSUNÇÃO, A. S.; BERNARDELLI, M. L. F. H. Educação popular e educação do/no campo: perspectivas para uma educação inclusiva - a Escola Família Agrícola em Sidrolândia - MS. Rev. Bras. Educ. Camp., Tocantinópolis, v. 2, n. 1, p. 294-322, 2017. DOI: http://dx.doi.org/10.20873/uft.25254863.2017v2n1p294 